\title{
Relationship between Students' Self-Regulation and Motivation in Universities
}

\author{
Saghir Ahmad \\ PhD Scholar, Lecturer (V) Institute of Education and Research, University of the Punjab, Lahore Pakistan \\ Dr. Ayesha Batool \\ Lecturer (V) Institute of Education and Research, University of the Punjab, Lahore Pakistan
}

\begin{abstract}
Self-regulated students are those who know about their metacognitive information of techniques and undertakings, just as self-learning. These students can move their metacognitive learning to all unique circumstances and substance zones. The research was conducted to explore the relationship between selfregulation and motivation among students at university level of Lahore. Researchers identify the perceptions of university students about their Self-Regulation and Motivation level. The major objective of the study was to investigate relationship between Self-Regulation and Motivation among Students at university level of Lahore. The total sample was consisted of 200 teachers. Majority students agreed that they usually keep track of progress toward their goals. According to them their behaviors are not different from other people. Students were agreeing that they tend to compare themselves with other people. They do not learn well from punishment. They said they have lot willpower. Some students said that they set goals for themself and keep track of progress. The $r$ - value shows that there was a significant positive association between self-regulation and motivation of students. Moreover, it is concluded that there was a moderate relationship between Self-Regulation and Motivation. There was significant difference in male and female students regarding self-regulation and motivation. There is need to organize or introduce such kind of activities to enhance the self-regulation and motivation among students.
\end{abstract}

Keywords: Self-regulated, self-learning, motivation, university.

DOI: $10.7176 / \mathrm{JCSD} / 54-02$

Publication date: December $31^{\text {st }} 2019$

\section{Introduction}

Social cognitive concept has given a hypothetical premise to the improvement of a model of self-managed learning in which individual, relevant and behavioral variables cooperate so as to offer students a chance to manage their learning (Bandura, 1986). Inside this structure, Pintrich (2000) characterized self-directed learning as a functioning useful procedure whereby students set objectives for their learning and afterward endeavor to screen, manage, and control their cognizance, inspiration, and behavior, guided and obliged by their objectives and the logical highlights of nature. These self-administrative exercises can intercede the connections among people and the unique situation, and their general accomplishment (Zimmerman, 2000).

Pintrich (2000) recognized four normal suppositions about self-managed learning. To begin with, selfcontrolled students accomplish more than inactively expend data that has been introduced to them by others. During the time spent learning, they effectively make techniques, objectives, and importance. Second, selfcontrolled students can somewhat, given the requirements forced by individual contrasts, settings, and science, screen and impact their activities. Third, self-directed students use objectives or models to survey the sufficiency of their learning and make changes if fundamental. Fourth, these students utilize automatic procedures to intervene the impact of outside settings and individual qualities in order to upgrade scholastic accomplishment and execution.

Self-directed students are those who know about their metacognitive information of techniques and undertakings, just as self-learning. These students can move their metacognitive learning to all unique circumstances and substance zones. For instance, learners are frequently gone up against with new errands that require information and abilities they have not yet learned. In this situation, they cannot depend on past learning to help them in their presentation on the new task. Learners who are self-controlled students will probably utilize methodologies to enable them to consider and take care of new issues. They will perceive that they need aptitude and use learned methodologies to help them in finishing testing undertakings. Further, learners who know their qualities and shortcomings and self-information, will modify their learning methodologies to be versatile to promote their learning and scholastic achievement (Pintrich, 2004).

It is noticed that learners who do not get express guidelines about the information and aptitudes that underlie self-managed adapting, in any case are creating types of self-controlled learning and may create types of self-directed discovering that are imperfect. In this way, it is conceivable that there are subjective and quantitative contrasts between the self-administrative procedures of powerful and less successful self-directed 
students. Baumeister (2002) stated under success in school or business emerges from an absence of selfguideline of behavior in these regions. Self-guideline alludes to certain cognizant and oblivious procedures by which the human mind activities command over the task of the state and its inner procedures. It is simply the key viewpoint through which the follows up on the living being. A few researchers think about self-guideline as an individual vitality asset. "Self-directed power" speaks to the inward assets important to hinder, survive or modify potential reactions that happen because of physiological procedures, schedules, learning or the curiosity of a circumstance.

Fonagy and Target (2002) expressed that self-guideline as a "key go between hereditary inclination, early beneficial encounters and working of the grown-up". The creators depict self-guideline recorded as the kid's capacity to "(1) control the reaction to stretch, (2) the capacity to keep up centered consideration and (3) the capacity to translate mental states". We grasp the view over self-guideline as fitness, accentuating specifically its procured part, attempting to decrease the "passivist" job of heredity in the improvement of human character. This conceptualization attempts to defeat the breaking points of prior models of self-guideline. Also attempts to put the inception of the marvel in the social displaying zone. Subsequently, cognizant self-guideline of conduct is accomplished to a great extent because of learning encounters. The demonstration of learning, despite the fact that it has a transcendent individual part is, notwithstanding, a social demonstration, including the socio-social interceded development of implications and connotation generation. We characterize self-managed learning as being "the fitness of students to design, execute and survey learning forms, including nonstop choices on subjective, inspirational and social parts of learning cycle process" (Deci, Hodges, Pierson, \& Tomassone, 1992).

Self-guideline is not a proportion of liquid insight, which is unaltered after a specific period throughout everyday life and not an individual trademark hereditarily decided or shaped in the early period. Learners learn self-guideline through experience and self-reflection, so it is ability. Educators can instruct in manners that help learners to wind up self-controlled students. Since self-guideline is not a character quality, they can control their emotions and feelings to improve learning and execution (Fonagy \& Target, 2002). Self-controlled learning is frequently seen as a go between among individual and logical attributes from one viewpoint and the dimension of learner performance on the other (Newman, 2009).

Countless investigations demonstrate that self-guideline is a key fixing in scholarly/learning performance. Ongoing instructive looks into demonstrate that self-regulated learning help students to accomplish the adaptiveness to the school atmosphere, essential for achieving the learning result. Oneself controlled student or the vital assistance searcher achieves a develop dimension of subjective and social improvement (Pintrich, 2000). This study provides for oneself managed the adaptability and mindfulness and motivation to learners.

\section{Significance of Study}

The findings of study have significant importance for the university administrators who believe students may self-regulate and motivate towards academic achievements. Learners learn self-guideline through experience and self-reflection, so it is ability. Educators can instruct in manners that help learners to wind up self-controlled students. Since self-guideline is not a character quality, they can control their emotions and feelings to improve learning and performance. The results of study are helpful to understand the level of self-regulation and motivation among university students. This study provides insights towards self-directed learning and this thing helpful to enhance the motivation to learn things independently effectively.

\section{Research Objectives}

The following were the objectives of the study to:

1. Explore the relationship between self-regulation and motivation among university students.

2. Identify the differences in students' perceptions regarding self-regulation and motivation on the basis of their demographic variables.

\section{Research Methodology}

In this study correlation research design was used. The study was descriptive and survey type in nature. The population of this study included the university students. The Population for this study consisted of university students of Lahore city. Convenient sampling technique was used to select sample from population. The data were collected from 200 university students. The instrumentation used for the study was developed by the researchers. The opinion of experts was taken for the validation of questionnaire before finalizing it. Questionnaire was developed regarding self-regulation and motivation. All statements designed at five-point Likert scale "Strongly Disagree, Disagree, Neutral, Agree and Strongly Agree". The reliability of the instrument was ensured by applying Cronbach Alpha. The researchers visited the institutions personally for data collection. Descriptive and inferential statistical techniques were used to analyze data. Pearson $r$ was used for relationship between self-regulation and motivation. Independent sample t-test and one way ANOVA were used to check demographic difference in students' perceptions regarding self-regulation and motivation. 


\section{Data Analysis}

The detail of data analysis is given below.

Table 1

Relationship between Students' Self-Regulation and Motivation

\begin{tabular}{|c|c|c|c|}
\hline Variables & & 1 & 2 \\
\hline \multirow{3}{*}{ Self-Regulation } & Pearson Correlation & 1 & $.366^{* *}$ \\
\hline & Sig. (2-tailed) & & .000 \\
\hline & $\mathrm{N}$ & 200 & 200 \\
\hline \multirow[t]{3}{*}{ Motivation } & Pearson Correlation & $.366^{* *}$ & 1 \\
\hline & Sig. (2-tailed) & .000 & \\
\hline & $\mathrm{N}$ & 200 & 200 \\
\hline
\end{tabular}

Table shows the results of Pearson correlation test which was performed to identify the relationship between Self-Regulation and Motivation. The $r$ - value shows that there was a significant correlation $r=.366^{* *}$ at $p=.000$. Moreover, it is concluded that there was a moderate positive relationship between self-regulation and motivation of students.

Table 2

Independent sample t-test was applied to compare the Self-Regulation and student's motivation scores for males and females

\begin{tabular}{llcccccc}
\hline Variables & gender & $N$ & Mean & $S D$ & $t$ & $d f$ & Sig. \\
\hline Self- & male & 78 & 50.12 & 6.666 & 2.214 & 198 & .028 \\
Regulation & female & 122 & 47.72 & 7.921 & & \multirow{2}{*}{198} & .007 \\
Motivation & male & 78 & 40.44 & 5.533 & -2.729 & & \\
& female & 122 & 42.99 & 6.988 & & &
\end{tabular}

Table shows that an independent sample t-test was applied to compare the Self-Regulation and student's motivation scores for males and females. There was no significant difference in Stress scores for males (M $=50.12, \mathrm{SD}=6.666)$ and females, $\mathrm{M}=47.72, \mathrm{SD}=7.921 ; \mathrm{t}(2.214)=198, \mathrm{p}=. .028$. Table shows that an independent sample t-test was applied to compare the Motivation scores for males and females. There was no significant difference in Motivation scores for males $(\mathrm{M}=40.44, \mathrm{SD}=5.533)$ and females, $\mathrm{M}=42.99, \mathrm{SD}=6.988$; $\mathrm{t}(-2.729)=198, \mathrm{p}=$. .007. It is concluded that there have no significant in independent sample t-test for difference of Stress and students Motivation based on male and female.

Table 3

One-way ANOVA was applied to know the difference in mean scores of Self-Regulation and Motivation on the basis of their semester.

\begin{tabular}{llccccc}
\hline Variables & & Sum of Squares & $d f$ & Mean Square & $F$ & Sig. \\
\hline Self-Regulation & Between Groups & 1516.776 & 3 & 505.592 & 10.142 & .000 \\
& Within Groups & 9770.419 & 196 & 49.849 & & \\
Motivation & Total & 11287.195 & 199 & & & \\
& Between Groups & 1353.056 & 3 & 451.019 & 12.237 & .000 \\
& Within Groups & 7223.939 & 196 & 36.857 & & \\
\hline
\end{tabular}

Table represents that one-way ANOVA was applied to know the difference in mean scores of selfregulation and motivation on the basis of their semester. Result show that there was no difference in mean scores of self-regulation on the basis of their semester $F(3,196)=10.142$ at $p=.000$ there was no significant difference in mean scores of self-regulation on students on the basis of their semester. Results show that there was difference in mean scores of students motivation $F(3,196)=12.237$ at $p=.000$. So, there was a significant difference in mean scores of motivation. It is concluded that there was no difference in mean scores of selfregulation and motivation based on semester. 
Table 4

One-way ANOVA was applied to know the difference in mean scores of Self-Regulation and Motivation on the basis of their departments

\begin{tabular}{llccccc}
\hline Variables & & Sum of Squares & $d f$ & Mean Square & $F$ & Sig. \\
\hline Self-Regulation & Between Groups & 2099.799 & 2 & 1049.900 & 22.512 & .000 \\
& Within Groups & 9187.396 & 197 & 46.637 & & \\
& Total & 11287.195 & 199 & & & \\
Motivation & Between Groups & 266.704 & 2 & 133.352 & 3.161 & .045 \\
& Within Groups & 8310.291 & 197 & 42.184 & & \\
& Total & 8576.995 & 199 & & & \\
\hline
\end{tabular}

Table shows that one-way ANOVA was applied to know the difference in mean scores of self-regulation and motivation on the basis of their department. Result show that there was no difference in mean scores of selfregulation on the basis of their department $F(1,096.537)=22.512$ at $p=.000$. There was no significant difference in mean scores of Self-Regulation on students on the basis of their department. One-way ANOVA was applied to know the difference in mean scores of students' motivation on the basis of their department. Result show that there was difference in mean scores of Self-Regulation of students F $(175.536)=3.161$ at $\mathrm{p}=.000$. So, there was a significant difference in mean scores of motivation. It is concluded that there was difference in mean scores of self-regulation and motivation based on department.

Table 5

One-way ANOVA was applied to know the difference in mean scores of Self-Regulation and Motivation on the basis of their CGPA

\begin{tabular}{llccccc}
\hline Variables & & Sum of Squares & $d f$ & Mean Square & $F$ & Sig. \\
\hline Self-Regulation & Between Groups & 229.506 & 3 & 76.502 & 1.356 & .258 \\
& Within Groups & 11057.689 & 196 & 56.417 & & \\
& Total & 11287.195 & 199 & & & \\
Motivation & Between Groups & 333.890 & 3 & 111.297 & 2.646 & .050 \\
& Within Groups & 8243.105 & 196 & 42.057 & & \\
& Total & 8576.995 & 199 & & & \\
\hline
\end{tabular}

Table indicates that one-way ANOVA was applied to know the difference in mean scores of self-regulation and motivation on the basis of their CGPA. Result show that there was no difference in mean scores of selfregulation on the basis of their CGPA $F(132.919)=1.356$ at $p=.258$. There was no significant difference in mean scores of self-regulation on students on the basis of their CGPA. Result show that there was difference in mean scores of students motivation $\mathrm{F}(153.354)=2.646$ at $\mathrm{p}=.050$. It is concluded that there was no difference in mean scores of self-regulation but difference in motivation of students based on CGPA.

\section{Conclusion}

The research was conducted to explore the relationship between self-regulation and motivation among students at university level of Lahore. Researchers identify the perceptions of university students about their selfregulation and motivation level. The major objective of the study was to investigate relationship between selfregulation and motivation among Students at university level of Lahore. The total sample was consisted of 200 teachers. Majority students agreed that they usually keep track of progress toward their goals. According to them their behaviors are not different from other people. Students were agree that they tend to compare themselves with other people. They do not learn well from punishment. They said they have a lot willpower. Some students said that they set goals for themself and keep track of progress. The $r$ - value shows that there was a significant correlation $r=.366^{* *}$ at $p=.000$. Moreover, it is concluded that there was a moderate relationship between SelfRegulation and Motivation. There was significant difference in male and female students regarding selfregulation and motivation. Result shows that there was no difference in mean scores of Self-Regulation on the basis of their semester. There was no significant difference in mean scores of Self-Regulation on students on the basis of their semester. There was significant difference in mean scores of Self-Regulation on students on the basis of their department. There was a significant difference in mean scores of Motivation. It is concluded that there was difference in mean scores of Self-Regulation and Motivation based on department. It is concluded that there was no difference in mean scores of Self-Regulation and Motivation based on CGPA.

\section{Recommendations}

On the basis of findings of study, the following recommendations were made:

1. There is agreement among the cognitive psychology researchers that teachers, in general, are unable to exercise their role with competence and quality without adequate training, as well as that there is a need for investing efforts in the teaching of self-regulated learning at all education levels, including in the 
university.

2. Identifying the characteristics of self-regulated learning among pedagogy students can be diagnostic and useful information for developing pedagogical training projects for this course, which might be directed toward strengthening the ability of these students to learn how to learn.

3. The acquisition of knowledge in teacher education courses cannot be merely content oriented in nature, as for future teachers to master the content being taught is not enough. They must also develop a wide range of knowledge, competences and skills that are influenced by personal beliefs, motivation, and the ability to regulate them in order to perform well the tasks required in their teaching practice.

4. Intrinsic motivation and extrinsic motivation activate the self-regulation process which in turn positively affects the learning outcomes. Teachers may know the intrinsic motivation and extrinsic motivation of the student and also practice in classroom.

5. Give some motivational lectures to the students that may help them to be motivated.

6. Teacher may be aware with the motivational strategies and theory which is appropriate with the situation.

\section{References}

Bandura, A. (1986). Social foundations of thought and action: A social cognitive theory. Englewood Cliffs, NJ: Prentice Hall.

Bandura, A. (1993). Perceived self-efficacy in cognitive development and functioning. Educational Psychologist, $28,117-148$.

Baumeister, R. F. (2002). Ego depletion and self-control failure: An energy model of the self's executive function. Journal Self and Identity, 1, 129-136.

Deci, E. L., Hodges, R., Pierson, L., \& Tomassone, J. (1992). Autonomy and competence as motivational factors in students with learning disabilities and emotional handicaps. Journal of Learning Disabilities, $25,457-471$.

Fonagy, P., \& Target, M. (2002). Early intervention and the development of self-regulation. Psychoanalytic Quarterly, 22, 307-335.

Newman, R. S. (2009), Help seeking, p. 298, in Schunk, D. H., Zimmerman, B. J. (2009). Self- regulation of learning and performance. Issues and Educational Applications, New York, NY: Routledge.

Pintrich, P. R. (2000). Educational psychology at the millennium: A look back and a look forward. Educational Psychologist, 35, 221-226.

Pintrich, P. R. (2004). A conceptual framework for assessing motivation and self-regulated learning in college students. Educational Psychology Review, 16(4), 385-407.

Zimmerman, B. J. (2000). Attaining self-regulation: a social cognitive perspective. In M.Boekaerts, P. R. Pintrich, \& M. Zeidner (Eds.), Handbook of self-regulation. San Diego:CA: Academic Press.

Zimmerman, B. J. (2002). Becoming a self-regulated learner: An overview. Theory into Practice, 41(2), 64-70. 